\title{
Zaratustra y el mal
}

ara el joven Friedrich Nietzsche, que emprende su vuelo en el pensar bajo la impronta de la filosofía de Schopenhauer, última gran metafísica de Occidente, la individuación es la raíz del mal en el mundo. El individuo, fragmento de la totalidad, vive sufriente y sumido en el dolor que le provoca su anhelo de alcanzar la unidad perdida y la imposibilidad trágica de integrarse a lo Uno primordial.

El nacimiento de la tragedia es, como sabemos, el texto donde Nietzsche explora esta intuición. Para el pensador alemán, la tragedia griega es precisamente la expresión del sufrimiento dionisíaco que se ha individualizado en el héroe trágico que busca afanosamente retornar a la unidad, dejando atrás los dolores del mundo. Cada tragedia es representación de Dionisio preso en la fatalidad de la individuación:

...el único Dionisio verdaderamente real aparece con una pluralidad de figuras, con la máscara de un héroe que lucha, y, por así decirlo, aparece preso en la red de la voluntad individual. En su forma de hablar y de actuar ahora, el dios que aparece se asemeja a un individuo que yerra, anhela y sufre... ${ }^{1}$

Pero para Nietzsche, el genio griego tuvo el acierto de representar las aflicciones del mundo y en particular de la individuación, a

1. Nietzsche, F., El nacimiento de la tragedia, Madrid, Alianza, 1973, p. 97. 
través precisamente del arte trágico que en un sólo momento reúne:

...el conocimiento básico de la unidad de todo lo existente, la consideración de la individuación como razón primordial del mal, el arte como alegre esperanza que pueda romperse el sortilegio de la individuación, como presentimiento de una unidad restablecida. ${ }^{2}$

De tal manera que, para Nietzsche, la tragedia es representación de la sólida voluntad griega que, de un solo golpe pudo, a través del arte, conciliar la fragmentación y la unidad.

Sin embargo, a los ojos de Nietzsche, el sol que brilló entre los antiguos griegos gozosos de la tragedia fue eclipsado por el optimismo teórico fundado por Sócrates que "...concede al saber la fuerza de una medicina universal y ve en el error el mal en sî". ${ }^{3}$ A partir de entonces, Nietzsche intuye y denuncia en el devenir occidental, desde la cultura griega hasta el mundo moderno, la ausencia de un arte trágico que reconcilie al individuo con la totalidad a la que pertenece. No obstante, el joven Nietzsche apuesta por un futuro distinto: una nueva cultura trágica que adviene y la cual reemplazará a la ciencia y, a través de un nuevo arte, instaurará la sabiduría en el mundo.

De lo señalado anteriormente y del contenido del primer libro de Nietzsche, me interesa destacar los tres elementos que ya fueron mencionados como integrantes de la tragedia griega, y que dan en buena medida solidez al planteamiento nietzscheano propuesto en El nacimiento de la tragedia. En primer lugar, la consideración de Nietzsche, muy vinculada con la filosofía de Schopenhauer, de la unidad de todo lo existente; luego, la consideración de que el estado de individuación es fuente de todo sufrimiento, de error y de anhelo insatisfecho y, por consiguiente, como algo que debe ser rechazado por sí mismo, en tanto es encarnación del mal; y, finalmen-

2. Ibid., pp. 97 y 98.

3. Ibid., p. 129.

132 C 
te, la consideración sobre el arte, en particular el arte trágico, como medio a través del cual se realiza la reconciliación entre la unidad perdida y la individuación. Me interesa destacar fundamentalmente estos puntos para intentar ver su evolución e incluso su trastrocamiento en el pensamiento nietzscheano expresado posteriormente en su texto Así habló Zaratustra.

Ciertamente es conocido el desplazamiento que el pensamiento de Nietzsche tuvo con respecto a su primera obra. ${ }^{4} \mathrm{El}$ primero en hacerlo notar fue el propio filósofo en el "Ensayo de autocrítica" que precede a las ediciones posteriores de su primer libro, donde se reprocha a sí mismo el haber

...oscurecido y estropeado con fórmulas schopenhauerianas unos presentimientos dionisíacos: a saber, jel haberme echado a perder en absoluto el grandioso problema griego, tal como a mí se me había aparecido, por la injerencia de las cosas modernísimas! ${ }^{5}$

Pero además, en el texto de Zaratustra, Nietzsche se distancia, aunque ahora poéticamente, de lo que en otro tiempo fue su vocación trasmundana:

En otro tiempo también Zaratustra proyectó su ilusión más allá del hombre, lo mismo que todos los trasmundanos. Obra de un dios sufriente y atormentado me parecía entonces el mundo.

Sueño me parecía entonces el mundo, e invención poética de un dios; humo coloreado ante los ojos de un ser divinamente insatisfecho.

Bien y mal, placer y dolor, y yo y tú -humo coloreado me parecía todo eso ante ojos creadores. El creador quiso apartar la vista de sí mismo, -entonces creó el mundo.

Ebrio placer es, para quien sufre, apartar la vista de su sufrimiento y perderse a sí mismo. me pareció en otros tiempos el mundo.

4. Vid., Fink, E., La filosofia de Nietzsche, Madrid, Alianza Universidad, 1976 y Deleuze, G., Nietzsche y la filosofía, Barcelona, Anagrama, 1971 entre otros.

5. Ibid., p. 34. 
Este mundo, eternamente imperfecto, imagen, e imagen imperfecta, de una contradicción eterna -un ebrio placer para su imperfecto creador: -así me pareció en otros tiempos el mundo.

Y así también, yo proyecté en otro tiempo mi ilusión más allá del hombre, lo mismo que todos los trasmundanos. ¿Más allá del hombre, en verdad? ${ }^{6}$

Zaratustra emerge entonces como la imagen de una conciencia que, volviendo la vista atrás, admite el haber participado en la ilusión de ir más allá del hombre y de haberse refugiado en la búsqueda de una totalidad supramundana. Admite también el haber mirado al mundo como una ensoñación, mera representación de una única voluntad, y el haber contemplado al bien y al mal, al placer y al dolor sólo como fantasmas y el haberse embriagado para apartar la vida del sufrimiento, para poder perderse a sí mismo. En suma, Zaratustra reconoce haberse proyectado, como todos los trasmundanos, fuera de la tierra misma.

Pero al mismo tiempo de admitir su otrora búsqueda trasmundana, Zaratustra va más allá. Se pregunta si tal anhelo se encontraba efectivamente por encima del hombre. La respuesta no se deja esperar:

¡Ay, hermanos, ese dios que yo creé era obra humana y demencia humana, como todos los dioses!

Hombre era, y nada más que un pobre fragmento de hombre y de yo: de mi propia ceniza y de mi propia brasa surgío ese fantasma, y ien verdad! ¡no vino a mí desde más allá!?

¿De dónde surgieron entonces las ensoñaciones? Para Zaratustra, fue el propio sufrimiento de donde los fantasmas provinieron, fue la incapacidad la que los creó y fueron producto de la fatiga:

6. Nietzsche, F., "Los trasmundanos", en Así habló Zaratustra, Madrid, Alianza, 1989, p. 56.

7. Ibid., p. 57.

$134 . C$ C A 
Fatiga que de un solo salto quiere llegar al final, de un salto mortal, una pobre fatiga ignorante, que ya no quiere ni querer: ella fue la que creó todos los dioses y todos los trasmundanos.

¡Creedme, hermanos míos! fue el cuerpo el que desesperó de la tierra, -con los dedos del espíritu trastornado palpaba las últimas paredes! ${ }^{8}$

Para Zaratustra, no es una entidad supraterrena la que gobierna el mundo, tampoco una voluntad ideal la que la sostiene. Pensar de esta manera es más bien producto del cansancio, del agobio, del desaliento, del dolor: el cuerpo abatido e impotente, inventa el ideal, inventa la trascendencia. A cambio Zaratustra, el ateo, enseña una nueva voluntad:

Mi yo me ha enseñado un nuevo orgullo, y yo se lo enseño a los hombres: ¡a dejar de esconder la cabeza en la arena de las cosas celestes, y a llevarla libremente, una cabeza terrena, la cual es la que crea el sentido de la tierra! Una nueva voluntad enseño yo a los hombres: ¡querer ese camino que el hombre ha recorrido a ciegas, y llamarlo bueno y no volver a salirse a hurtadillas de él, como hacen los enfermos y moribundos!

Enfermos y moribundos eran los que despreciaron el cuerpo y la tierra y los que inventaron las cosas celestes y las gotas de sangre redentora: ipero incluso estos dulces y sombríos venenos los tomaron del cuerpo y la tierra! ${ }^{9}$

A diferencia de las ensoñaciones que gobiernan a El nacimiento de la tragedia, Zaratustra mira entonces ya no en la dirección de las esencias y la unidad fundamental, ya no es presa de una embriaguez que lo pierde a sí mismo, sino que vuelve sus ojos hacia la tierra misma y condena a quienes han inventado lo trasmundano. Desde las primeras páginas Zaratustra anuncia su nueva enseñanza: "Yo os conjuro, hermanos míos, permaneced fieles a la tierra y no creáis a quienes os hablan de esperanzas sobreterrenales! Son envenenadores, lo sepan o no." 10

8. Ibidem.

9. Ibid., p. 58.

10. Cfr. Nietzsche, F., "Prólogo", en Así habló Zaratustra. 
Para Zaratustra, el mundo verdadero no se encuentra entonces fuera del mundo mismo, tampoco fuera del tiempo y el espacio. No tiene su sostén en las ideas, ni en Dios, ni en un reino celestial al que habría que dirigirse 0 en el que se podría encontrar refugio. Pasando por encima de quienes apelan a una realidad supraterrenal, Zaratustra apuesta por la tierra, otrora desvalorizada por las interpretaciones trasmundanas: el verdadero, el único ámbito de nuestra vida es la tierra, lo terrenal; el único espacio existente es el mundo que conocemos, pero que a veces queremos interpretar a partir del cielo: es la tierra el único trasfondo que sostiene y produce nuestra existencia: nosotros mismos somos tierra y por ello debemos aprender y atenernos a su sentido. No es que la tierra pase a ocupar la dimensión de Dios o de alguna idea propia de los trasmundanos; esto es, no se trata de concebirla como mero sostén del mundo que conocemos. La tierra es más, mucho más que un objeto al que hay que conocer o dominar. Como señala Eugen Fink:

Nietzsche no concibe la tierra como algo meramente existente, sino como lo que hace surgir todo de sí, como el seno de todas las cosas, como el movimiento de producción, del que surge lo existente múltiple, individualizado y limitado, y adquiere perfil, figura y consistencia. Nietzsche concibe la tierra como un poder creador, como poiésis. ${ }^{11}$

La tierra es así, para Zaratustra, la única realidad existente. A ella pertenecen todas las cosas. Más aún, ella las produce y las cosas mismas forman parte de la tierra. Nosotros mismos, junto con el cielo, el mar y el rayo somos tierra. Por ello, Zaratustra enseña a los hombres:

¡Permaneced fieles a la tierra, hermanos míos, con el poder de nuestra virtud! :Vuestro amor que hace regalos y vuestro conocimiento sirvan al sentido de la tierra!

11. Fink, E., Op. cit., p. 91. 
Esto os ruego y a ello os conjuro.

¡No dejéis que vuestra virtud huya de las cosas terrenas y bata las alas hacia paredes eternas! ¡Ay, ha habido siempre tanta virtud que se ha perdido volando!

Conducid de nuevo a la tierra, como hago yo, a la virtud que se ha perdido volando -sí, conducidla de nuevo al cuerpo y a la tierra; ¡para que sea la tierra su sentido, su sentido humano! ${ }^{12}$

Pero precisamente porque nosotros, nuestro cuerpo mismo es tierra, ya no es posible pensar, como el soñador de El nacimiento de la tragedia, que la individuación sea origen del mal en el mundo. La tierra nos ha producido como parte de ella misma. Debemos oír por ello su sentido y mantenernos fieles a él, por encima de los trasmundanos. Zaratustra advierte: “¡Ahora lo más horrible es delinquir contra la tierra y apreciar las entrañas de lo inescrutable más que el sentido de aquélla!'13

Un camino inicial es alejarse de los trasmundanos: "Son despreciadores del cuerpo, son moribundos y están, ellos también, envenenados, la tierra está cansada de ellos. ¡Ojalá desaparezcan!"’14

Para Zaratustra, el mal ya no está en la individuación, tal como Nietzsche lo mostraba en la incursión que realizó en la Grecia antigua bajo la impronta schopenhaueriana. Ya no se deposita en el horror que producen los dolores del mundo. Ciertamente hay un mal y, sin duda, se deposita en los individuos; sin embargo, no es producto de la individuación misma. Es, más bien, en primera instancia, resultado de la actividad de los trasmundanos cuya hechura ha sido, a su vez, producto de la fatiga, de su agobio, de su debilidad, de su desaliento, de su dolor. En suma, resultado de su desprecio por la vida.

Para Zaratustra, como vimos arriba, ese auténtico mal, ese desprecio por la vida, esa fatiga fueron el origen de los ideales, de las

12. Nietzsche, F., Así habló Zaratustra, p. 121.

13. Ibid., p. 35.

14. Ibid., p. 34. 
esencias, de Dios mismo. De un Dios que se enseñoreó por encima de todos los otros y se proclamó a sí mismo el único. De un Dios que ordenó la obediencia a todos los hombres, que prometió un reino celestial por encima de la tierra misma. De un Dios que quiso constituirse en el pastor de los hombres y hacer de éstos un solo rebaño.

Pero Zaratustra sabe, de principio, que ese Dios ha muerto y que ha sido victimado precisamente por los hombres mismos. Pero además, que si bien los hombres se han desembarazado del supremo pastor, no han hecho lo mismo con su condición de rebaño. De tal manera que, para Zaratustra, los hombres no se han desembarazado tampoco del verdadero mal, de su milenario aprendizaje trasmundano. Pero como vemos nuevamente, este mal no radica en la individuación como en El nacimiento de la tragedia, sino en la carga que el individuo sostiene. En particular, la carga que sostiene el hombre moderno, que para Zaratustra es el último hombre:

¡Mirad! Yo os muestro el último hombre.

“¿Qué es amor? ¿Qué es creación? ¿Qué es anhelo? ¿Qué es estrella?" -así pregunta el último hombre y parpadea.

La tierra se ha vuelto pequeña entonces, y sobre ella da saltos el último hombre, que todo lo empequeñece. Su estirpe es indestructible, como el pulgón; el último hombre es el que más tiempo vive.

"Nosotros hemos inventado la felicidad" -dicen los últimos hombres y parparlean.

Han abandonado las comarcas donde era duro vivir: pues la gente necesita calor. La gente ama incluso al vecino y se restriega contra él: pues necesita calor. Enfermar y desconfiar consideránlo pecaminoso: la gente camina con cuidado. ¡Un tonto es quien sigue tropezando con piedras o con hombres!...

La gente continúa trabajando, pues el trabajo es un entretenimiento. Mas procura que el entretenimiento no canse...

¡Ningún pastor y un solo rebaño! Todos quieren lo mismo, todos son iguales: quien tiene sentimientos distintos marcha voluntariamente al manicomio... ${ }^{15}$

15. Ibid., p. 39.

138 C 
La carga que sostiene el hombre moderno es donde radica el auténtico mal. Es ahí donde se encuentra nuestro más terrible padecimiento y no en ser parte de la tierra. De hecho, el enemigo primordial de Zaratustra es también el espíritu de la pesadez, encarnación del mal de nuestro tiempo: "Y cuando vi a mi demonio lo encontré serio, grave, profundo, solemne: era el espíritu de la pesadez, -él hace caer todas las cosas." "16

Así también cuando Zaratustra busca un nuevo ascenso, el espíritu de la pesadez reaparece acechándole:

Hacia arriba: -a pesar del espíritu que tiraba hacia abajo, hacia el abismo, ese espíritu de la pesadez, mi demonio y enemigo capital.

Hacia arriba: aunque sobre mí iba sentado ese espíritu, mitad enano, mitad topo: paralítico, paralizante; dejando caer plomo en mi oído, pensamientos -gotas de plomo en mi cerebro. ${ }^{17}$

Pero así como el espíritu de la pesadez se monta en los hombros de Zaratustra, también lo hace desde muy pronto en cada uno de los hombres modernos:

Y nosotros -jnosotros llevamos fielmente cargada la dote que nos dan, sobre duros hombros y por ásperas montañas! Y si sudamos se nos dice: "¡iś, la vida es una carga pesada!"

¡Pero sólo el hombre es para sí mismo una carga pesada! Y esto porque lleva cargadas sobre sus hombros demasiadas cosas ajenas. Semejante al camello, se arrodilla y se deja cargar bien.

Sobre todo el hombre fuerte, paciente, en el que habita la veneración: demasiadas palabras ajenas y demasiados pesados valores ajenos carga sobre sí, -entonces la vida le parece un desierto! ${ }^{18}$

Pero como podemos presentir, el espíritu de la pesadez, el auténtico mal, tiene múltiples expresiones, aparece bajo innumerables

16. Ibid., p. 71.

17. Ibid., p. 270.

18. Ibidem. 
rostros que hacen pesada y densa la existencia. Encarna, como ya sabemos, en los trasmundanos y en la esperanza de una vida después de la muerte. Es el medio para el propio cultivo del último hombre que se regodea en el rebaño. Surge como resultado de la fatiga, del aturdimiento, del agobio, del agotamiento, del fastidio, del ahogo. Condena al cuerpo, a sus placeres y a sus deseos: lo previene de caer en tentación. Encarna en los predicadores de la muerte: aquellos que sostienen que "la vida no es más que sufrimiento", que "la voluptuosidad es pecado", que "dar a luz es cosa ardua", que "la compasión es lo que hace falta". Es propia de la hiperdiligencia moderna que todo lo agota en el instante. Habita en el mercado donde todo tiene un precio y donde los últimos hombres se apretujan para obtener un pan más azucarado que el que tiene aquel que está a su lado. Zaratustra ubica este mal entre los sacerdotes, los compasivos, la chusma y a veces también entre los doctos. El espíritu de la pesadez es el que gobierna el alma de aquellos que sólo aspiran a un simple bienestar, a una simple comodidad, pero también conduce el alma de los déspotas, la de aquellos que predican la no acción y el no tener deseos. El espíritu de la pesadez impera en el alma del parásito, "el más repugnante bicho humano" que Zaratustra ha encontrado: "...este no ha querido amar, pero sí vivir del amor." "19 Claro está que nuestro mal también se encuentra en el conformismo, en el apretujarse, en la hiperprotección, en la muerte en vida, en la falta de esfuerzo, en la inacción. Ronda al individuo que se abandona, produce inestabilidad enferma, falta de firmeza, incapacidad de comprometerse con las propias decisiones; lleva a los hombres a vigilarse unos a otros, los conduce al mercado y a la consideración de que lo único importante es jugarse en la producción y en el consumo. Pero además, el espíritu de la pesadez gusta también de encontrar los medios para asegurar su supervivencia: a veces construye una razón, que como el viejo Dios, se autonombra

19. Ibid., p. 271.

140) 
única, todopoderosa y con la capacidad de condenar todo aquello que es diferente.

Enfrentar el espíritu de la pesadez es tarea que se propone Zaratustra. Vimos arriba que, frente a la voluntad trasmundana, Zaratustra opta por el sentido de la tierra, que implica para cada uno de los hombres el asumir su pertenencia a la tierra misma. Cada uno de nosotros carga en sí mismo, de una u otra forma, el plomo del espíritu de la pesadez. Por ello, Zaratustra no apela a la humanidad de sus discursos. Se dirige más bien a cada hombre. El individuo no es encarnación del mal, en tanto producto de la individuación; lleva en sí mismo el mal en tanto es sujeto del espíritu de la pesadez. Pero por ello, el individuo es el que puede liberarse de él y decir sí a la existencia, asumiendo el sentido de la tierra que, como nos lo hace ver Eugen Fink es, para Nietzsche, poiésis, creación. Zaratustra apela así a la creación de los individuos mismos, asumiendo el sentido de la tierra: "Vuestro espíritu y vuestra virtud sirvan al sentido de la tierra, hermanos míos: iy el valor de todas las cosas sea establecido de nuevo por vosotros! ¡Por eso debéis ser creadores!"20

Ciertamente y como podemos presentir, para Zaratustra el camino no es fácil: "...quien tiene que ser un creador en el bien y en el mal: en verdad, ése tiene que ser antes un aniquilador y quebrantar valores." ${ }^{21}$

Sin embargo, para Zaratustra no es de la venganza de donde puede venir la creación. Zaratustra quiere algo más que un espíritu reactivo: "...pues que el hombre sea redimido de la venganza: ése es para mí el puente hacia la suprema esperanza y un arco iris después de prolongadas tempestades." ${ }^{22}$

20. Ibid., p. 121.

21. Ibid., p. 172.

22. Ibid., p. 151. Véase el ensayo de interpretación que Martín Heidegger hace de este aforismo en el artículo titulado "Quién es el Zaratustra de Nietzsche", en Heidegger, M., Conferencias y artículos, Barcelona, Ediciones del Serbal, 1994. 
Zaratustra quiere inocencia en la creación más que un espíritu reactivo: “Dónde hay inocencia? Allí donde hay voluntad de engendrar. $\mathrm{Y}$ el que quiere crear por encima de sí mismo, ése tiene para mí la voluntad más pura." ${ }^{23}$

Pero para crear, para poder acceder a la inocencia que permite la creación, como podemos suponerlo, es menester vencer al mal: el espíritu de la pesadez. Y, a los ojos de Zaratustra, un paso fundamental para llegar a ello es algo lejano a lo que el propio espiritu de la pesadez ha enseñado milenariamente. Para crear, Zaratustra enseña amarse a sí mismo:

Mas quien quiera hacerse ligero y transformarse en un pájaro tiene que amarse a sí mismo: así enseño yo.

No, ciertamente, con el amor de los enfermos y calenturientos: ¡pues en ellos hasta el amor propio exhala mal olor!

Hay que aprender a amarse a sí mismo -así enseño yo- con un amor saludable y sano: a soportar estar consigo mismo y a no andar vagabundeando de un sitio para otro. ${ }^{24}$

Aunque claro está, el amor a sí mismo no basta para la creación. Lis necesario aguardarse a sí mismo y aprender a volar: "Y ésta es mi doctrina: quien quiera aprender alguna vez a volar tiene que aprender primero a tenerse en pie y a caminar y a correr y a trepar y a bailar: -jel volar no se coge al vuelo!" ${ }^{25}$

No por ello, Zaratustra señala un único camino. Muestra más bien las marcas del suyo y enseña a tomar el propio, a crear, como crea la tierra, el camino de uno mismo: "Éste es mi camino, -¿̨dónde está el vuestro?’ así respondía yo a quienes me preguntaban `por el camino'. ¡El camino, en efecto, -no existe!"26

23. Nietzsche, F., Así habló Zaratustra, p. 182.

24. Ibid., p. 271.

25. Ibid., p. 272.

26. Ibidem.

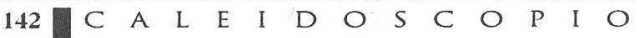


Con la invitación de Zaratustra a la creación del propio camino, se establece un nuevo deslizamiento realizado por Nietzsche con respecto a El nacimiento de la tragedia. Recordemos que ahí la apuesta era a favor del arte, fundamentalmente del arte trágico, que Nietzsche creía ver aproximarse en el horizonte del Occidente moderno. Ahora, en Así habló Zaratustra, Nietzsche apuesta también por la creación, pero no únicamente la que pertenece al dominio de lo que tradicionalmente llamamos arte. En todo caso, objeto de creación es la vida misma, en cada caso la de cada individuo. Una creación que, partiendo del sentido de la tierra y no de una voluntad trasmundana, se atreve a pensar que el mal no radica en la individuación sino en el espíritu de la pesadez que cada uno debe enfrentar y vencer a fin de decir cada vez sí a la vida. Tal como lo hace Zaratustra en cada momento de su trayecto y también al final, cuando Zaratustra ya con la cabeza blanca vuelve a comenzar de nuevo:

Mi sufrimiento y mi compasión - ¡qué importan! ¿Aspiro yo acaso a mi felicidad? ¡Yo aspiro a mi obra!

¡Bien! El león ha llegado, mis hijos están cerca, Zaratustra ya está maduro, mi hora ha llegado: - Ésta es mi mañana, mi día comienza: ¡asciende, pues, asciende tú, gran mediodía!

En aquella ocasión así habló Zaratustra. :

27. Ibid., p. 433. 
